\title{
ZE SZTUĆCEM NA RYSIA, CZYLI PAN TADEUSZ PO NIEMIECKU
}

\footnotetext{
Zarys treści. Wielkie zainteresowanie kulturą polską, szczególnie nasilone w pierwszej połowie XIX wieku, zaowocowało sześcioma pełnymi wersjami tłumaczeń Pana Tadeusza na język niemiecki. W tym artykule porównujemy sposób podejścia autorów czterech najnowszych tłumaczeń do przekładu polskich realiów kulturowych, konstytuujących odrębność etnoretoryczną. Należą do nich m.in. określenia potraw, broni, strojów, urzędów czy roślin.
}

W latach trzydziestych XIX wieku na terenie dzisiejszych Niemiec wystąpił fenomen zwany „Polenschwärmerei”. Pojęcie to wspomina R. D. Kluge, profesor slawistyki w Tybindze, wydawca książki Von Polen, Poesie und Politik (Kluge 1999). Powstanie listopadowe, które okazało się daremnym bohaterskim zrywem przeciw rosyjskiemu zaborcy, wywołało w szerokich kręgach w całej Europie uznanie dla Polski i poczucie solidarności. Sam Mickiewicz na początku kwietnia 1833 roku pisał: „In Deutschland bedeutet Freund der Polen zu sein dasselbe, wie Freund der Freiheit” (Mickiewicz 1955a: 406). W ten sposób polscy emigranci, będący zarazem intelektualistami i powstańcami, stali się symbolem walki wywołującej żywe uczucia. Te właśnie okoliczności spowodowały, iż utwory Adama Mickiewicza spotkały się z serdecznym przyjęciem u czytelników.

Jedno z dzieł Mickiewicza wzbudzało szczególne zainteresowanie nie tylko literatów, ale i wydawców oraz czytelników, wpływając na popularność autora i okazywane mu uznanie. Liczne tłumaczenia (sześć komplet-

\footnotetext{
${ }^{1}$ Czasem określany nawet jako „Affenliebe”, jak np. u Heinricha Piebrocka (2000).
} 
nych wersji, ostatnia z roku 1977) potwierdzają, że nadal znajduje ono entuzjastycznych odbiorców. Chodzi o Pana Tadeusza, napisanego na emigracji w Paryżu w 1834 roku - wyznanie miłości do ojczyzny, która pozostawała w poecie jako kraj dzieciństwa taką, jaką chciał ją chronić w swoim sercu. Przetłumaczenie tak monumentalnego dzieła można uznać za prawdziwe wyzwanie, które podjęło jednak kilkoro śmiałków (znalazła się w tym gronie również jedna niewiasta), a każdy z nich miał inną koncepcję jego przełożenia. I zapewne możemy spodziewać się dalszych prób, gdyż, jak stwierdził August Wilhelm Schlegel:

Es ist fast unmöglich, bei poetischen Nachbildungen alles auf einmal zu leisten, wie es in diesem Fache nicht anständig ist, irgend etwas anderes als Meisterstücke zu übersetzen, so hat man dagegen an diesen immerfort zu tun, um ihre Übertragung der Vollkommenheit näher zu bringen, die eigentlich eine unendliche Aufgabe ist ${ }^{2}$ (Schlegel 1846: 414).

Już Humboldt przed dwustu laty pisał, że każde tłumaczenie jest zadaniem nie do spełnienia. Każdy tłumacz jest bowiem pośrednikiem pomiędzy językami, narodami, ideologiami, literaturami i kulturami. Musi więc przezwyciężać bariery kulturowe i językowe, relatywność w pojmowaniu, rozumowaniu i postrzeganiu świata spowodowane wzrastaniem w określonym środowisku językowym. Wszystkie te trudne zadania musi on wypełniać w najmniej sprzyjających warunkach - ponaglany przez terminy wydawnicze, sytuację na rynku książki, własne potrzeby finansowe. Przy tym będzie zawsze napotykał słowa oddające obcość kulturową użytkowników języka wyjściowego w leksemach, które tylko częściowo i nierzadko z trudem są przetłumaczalne. Takie leksemy nazywamy realiami.

Przy wielu określeniach tłumacz musi sobie zadawać pytanie, na ile w ogóle istnieje możliwość teoretyczna i praktyczna wiernego oddania realiów kulturowych. W wypadku Pana Tadeusza, który dla wielu jest esencją polskości, owa etnoretoryczna odrębność (Sławkowa, Warchoł 2000: 25), będąca dla tłumaczy swoistym wyzwaniem, wyraża się przede wszystkim w bogactwie realiów, których „zapis” istnieje w zasobach leksykalnych polszczyzny.

${ }^{2}$ „Jest prawie niemożliwością, aby przy przekładach poetyckich dokonać wszystkiego na raz, tak jak nie wypada w tym fachu tłumaczyć czegoś innego niż arcydzieła, więc trzeba stale nad nimi pracować, aby tłumaczenie przybliżyć do doskonałości, która stanowi nieustające zadanie” (tłum. aut.). 
W tekstach natury kulturoznawczej i dziełach literackich nacechowanych specyfiką kulturową danego kraju znajduje się szczególne bogactwo wyrażeń i treści typowych dla danego obszaru (politycznych, instytucjonalnych, społeczno-kulturowych, botanicznych i geograficznych), jak obyczaje, tradycje, rytuały czy nawiązania historyczne. Elementy specyficzne kulturowo nieodzownie pojawią się w każdym tekście. Mówi o tym również Werner Koller:

Wenn gesagt wird, dass Sprache und Kultur aufs engste miteinander verknüpft sind, so schließt das nicht aus, dass es auf der einen Seite linguistische Phänomene gibt, die kulturunabhängig sind [...], auf der anderen Seite eindeutig nicht-linguistische, kulturbestimmte Phänomene, wie etwa Kleidung, Essgewohnheiten $^{3}$ (Koller 1997: 163, 164).

Słusznie zauważa Barchudarow, że tego typu nieregularne odpowiedniki sprawiają największy kłopot przy tłumaczeniu, a nawet uchodzą za nieprzetłumaczalne (Koller 1997: 184).

Koller stwierdza, że właściwie takie pojęcia może zrozumieć jedynie ten, kto dokładnie zna kulturę, w której one występują (Koller 1997: 177). Stąd należałoby wymagać od tłumacza, próbującego się zmierzyć z eposem narodowym, kompetencji nie tylko w zakresie leksykalno-gramatycznym, ale i rzetelnej znajomości dziejów i zawiłości politycznych danego regionu, jego przyrody, klimatu, obyczajów; a tego często brak i u rodzimych użytkowników języka. Tymczasem tłumaczom niekiedy można zarzucić niewystarczającą znajomość nawet własnej kultury i nieporadność w języku ojczystym.

Na szczęście do dyspozycji translatorów są przeróżne kompendia wiedzy ze wszystkich dziedzin; wertowanie ich i przyswajanie sobie szeregu nowych pojęć jest jednak doprawdy mrówczą pracą. Trudno się dziwić autorom tłumaczeń, którzy są wszak tylko ludźmi, że idą na łatwiznę opuszczeń i uproszczeń!

Pomocą w tej trudnej materii są również liczne opracowania teoretyczne z zakresu translatoryki, porządkujące zagadnienia przekładu realiów.

Eugene A. Nida na przykład, zwany ojcem ekwiwalencji dynamicznej, zadał sobie trud usystematyzowania problemów, które występują przy próbie nazwania zjawisk obcych kulturowo. Wymienia trzy główne trudności:

3 „Jeśli mówi się, że język i kultura są najściślej ze sobą powiązane, to fakt ten nie wyklucza istnienia z jednej strony zjawisk lingwistycznych niezależnych od kultury, a z drugiej jednoznacznie nielingwistycznych kulturowych zjawisk, takich jak ubiór, zwyczaje kulinarne" (tłum. aut.). 
1) w kulturze języka docelowego nie występuje element odpowiadający elementowi kultury wyjściowej;

2) język oryginału i język docelowy różnią się tym, że nie te same elementy są obligatoryjne lub fakultatywne;

3) określone znaki dla określonych treści występują w języku wyjściowym częściej niż ich odpowiedniki w języku docelowym (za: Koller 1997: 156-157).

Tłumacz dysponuje kilkoma możliwościami w obliczu takiej luki językowej. „Jeśli powstaje taka luka, można brakujący termin zastąpić przez zapożyczenia, kalki językowe, neologizmy, przesunięcia znaczenia, jak i w ostateczności przez opis" (Koller 1997: 185) ${ }^{4}$. Ostatnia możliwość przyczynia się do tego, że przekłady właściwie zawsze są dłuższe od oryginału.

Tłumacz musi sam podjąć decyzję, która z powyższych możliwości jest właściwa; wybór częstokroć jest trudny i uwarunkowany wieloma czynnikami. Zwłaszcza przy tłumaczeniu tekstów poetyckich staje się przed dylematem odejścia od dosłowności przekładu na korzyść zachowania formy utworu, jego wersyfikacji, rytmiki czy rymów.

Brak tu miejsca na dalsze rozważania teoretyczne; teoria nie uwzględnia zresztą ludzkiej omylności i niekompetencji w specjalistycznych dziedzinach. Oto garść przykładów ${ }^{5}$ na to, jak nieznajomość rzeczy i brak dociekliwości może wpłynąć na obraz rzeczywistości wykreowany w przekładzie, a tym samym doprowadzić do powstania figur semantycznych odbiegających od tych, które ukonstytuowały się wcześniej u odbiorców tekstu oryginalnego.

W tabeli przyciemniono wszystkie pola, w których pojawiają się uogólnienia, uproszczenia, przemieszanie pojęć i niejasności wynikające z bezpośredniego przejęcia polskich określeń niezaopatrzonych w jakiekolwiek objaśnienia. Czasem odpowiednika po prostu brak - te pola, dokumentujące niedokładność czy też lenistwo tłumacza, również zacieniowano. Dodatkowo wytłuszczono niewłaściwie użyte ekwiwalenty, które ewidentnie wprowadzają czytelnika w błąd.

${ }^{4}$ Tłumaczenie autorek artykułu

${ }^{5} \mathrm{~W}$ tabeli przedstawiono jedynie wybrane realia $\mathrm{z}$ różnych dziedzin (m. in. uzbrojenie, administracja, botanika, kulinaria). Więcej o nazwach roślin i potraw w tłumaczeniach Pana Tadeusza patrz: Pazdan, Buk 2003; 2004. 


\begin{tabular}{|c|c|c|c|c|}
\hline $\begin{array}{c}\text { Pan } \\
\text { Tadeusz }^{\mathrm{I}}\end{array}$ & Lipiner & Panitz & Buddensieg & Friedenberg \\
\hline 1 & 2 & 3 & 4 & 5 \\
\hline Szlachta & Edle & Szlachta & Szlachta & $\begin{array}{l}\text { Edelleute, } \\
\text { Zaunadel }\end{array}$ \\
\hline Szlachcic & $\begin{array}{c}\text { Schlachta } \\
\text { Junker Bruder } \\
\text { Schlachcic }\end{array}$ & $\begin{array}{c}\text { polnischer } \\
\text { Edelmann } \\
\text { Schlachtschitz }\end{array}$ & $\begin{array}{l}\text { Junker, } \\
\text { Schlachcic }\end{array}$ & $\begin{array}{l}\text { Adelsbruder, } \\
\text { Edelmann }\end{array}$ \\
\hline Tur, $\dot{z} u b r$ & $\begin{array}{l}\text { Wisent, } \\
\text { Ur, Büffel }\end{array}$ & $\begin{array}{c}\text { Auerochs, Bison, } \\
\text { Wisent }\end{array}$ & $\begin{array}{c}\text { Auerochse, } \\
\text { Wisent }\end{array}$ & $\begin{array}{l}\text { Wisent, Aueroch- } \\
\text { se, Bison, Luchs }\end{array}$ \\
\hline Sztuciec & Stutzen & Gewehr & Stutzen & Besteck \\
\hline Karabela & $\begin{array}{c}\text { Säbel } \\
\text { Karabelle }\end{array}$ & $\begin{array}{l}\text { krummer Säbel } \\
\text { Schwert }\end{array}$ & Säbel, Gewehr & $\begin{array}{l}\text { Krummsäbel, } \\
\text { Säbel (polnischer) }\end{array}$ \\
\hline Szabla & $\begin{array}{l}\text { Schwert, Klinge } \\
\text { krummer Säbel }\end{array}$ & Säbel & $\begin{array}{c}\text { Säbel } \\
\text { krummer Säbel }\end{array}$ & $\begin{array}{l}\text { Degen, Säbel, } \\
\text { krummer Säbel }\end{array}$ \\
\hline $\begin{array}{l}\text { Czamarka } \\
\text { krakowska }\end{array}$ & Czamarka & - & $\begin{array}{c}\text { Krakauer Tracht } \\
\text { Krakauer } \\
\text { Tuchrock } \\
\end{array}$ & Schnürrock \\
\hline Kontusz & Kontusz & Kontusz & $\begin{array}{l}\text { Kontusch, } \\
\text { Kontusz }\end{array}$ & $\begin{array}{c}\text { Rock, Oberkleid, } \\
\text { Kontusz }\end{array}$ \\
\hline Bielizna & weißes Kleid & $\begin{array}{l}\text { Morgenkleid, } \\
\text { weißes Kleid }\end{array}$ & $\begin{array}{c}\text { weißes langes } \\
\text { Gewand, Haus- } \\
\text { kleid } \\
\end{array}$ & $\begin{array}{l}\text { Morgenkleid, } \\
\text { Unterkleid }\end{array}$ \\
\hline Ziemianie & Landedelleute & Adel auf dem Lande & Gutsherren & Gutsbesitzer \\
\hline Woźny & $\begin{array}{c}\text { Protasius } \\
\text { letzter } \\
\text { Gerichtfron }\end{array}$ & $\begin{array}{c}\text { Woźny } \\
\text { letzter Woźny } \\
\text { seiner Art }\end{array}$ & $\begin{array}{c}\text { Woźny, letzter } \\
\text { Bote des Tribu- } \\
\text { nals in Litauen }\end{array}$ & $\begin{array}{l}\text { Gerichtsfron, } \\
\text { Litauens letzter } \\
\text { Gerichtsfron }\end{array}$ \\
\hline Dwór & Haus & Haus & Gutshof & Gutshof \\
\hline Dziewanna & Wollkraut & $\begin{array}{l}\text { Königskerzen } \\
\text { mit blauen und } \\
\text { roten Blüten }\end{array}$ & $\begin{array}{c}\text { gelbe } \\
\text { Königskerzen }\end{array}$ & $\begin{array}{c}\text { gelbe } \\
\text { Königskerzen }\end{array}$ \\
\hline Kalina & Holunder & Heidelbeer & Schneeball & Schneeball \\
\hline Grab & Jochbaum & Buche & Hagbaum & Jungbuche \\
\hline Lisiczki & Fuchspilz & „Fuchspilz” & Pffiferling & Pfefferling \\
\hline
\end{tabular}

${ }^{\text {I }} \mathrm{W}$ tabeli zostały pominięte przykłady z dwóch najstarszych tłumaczeń. Pełne tytuły przekładów, jak również użyte przez nas wydanie polskie wymienione są w bibliografii.

II Należy zwrócić uwagę, że określenie to wywołuje u Niemca skojarzenia z niemieckim słowem Schlachter, oznaczającym rzeźnika, co bynajmniej nie kojarzy się ze szlachetnością. 


\begin{tabular}{|c|c|c|c|c|}
\hline 1 & 2 & 3 & 4 & 5 \\
\hline Surojadki & $\begin{array}{c}\text { Blätter- } \\
\text { schwämme }\end{array}$ & $\begin{array}{c}\text { ein Pilz mit Rot } \\
\text { und Goldgeflecht }\end{array}$ & Blätterpilze & $\begin{array}{l}\text { Blätterschwäm- } \\
\text { me }\end{array}$ \\
\hline Szczyr & Bingelkraut & Strauch & Hirse & Bingelkraut \\
\hline Łopuch & Wegerich & Wegerich & Rettich, Klette & $\begin{array}{l}\text { Ackerrettich, } \\
\text { Klette }\end{array}$ \\
\hline Niezabudki & $\begin{array}{l}\text { Vergißmein- } \\
\text { nicht }\end{array}$ & Blümchen & $\begin{array}{l}\text { Vergißmein- } \\
\text { nicht }\end{array}$ & Vergissmeinnicht \\
\hline Szatwia & Salbei & Heilkräuter & Salbei & Salbei \\
\hline Świerzop & Rübsamen & Senf & Rübsen & Rübsen \\
\hline Dzięcielina ${ }^{\mathrm{III}}$ & Klee & Quendel & Quendel & Quendel \\
\hline Owies & Hafer & Hafer & Hafer & Weizen \\
\hline Zrazy & Klöpse & Schnitzel & Fleischklöße & Gulasch \\
\hline Bigos & Bigos & $\begin{array}{l}\text { "Bigos", den die } \\
\text { Ungarn „Gu- } \\
\text { lasch" nennen }\end{array}$ & Bigos & Bigos \\
\hline $\begin{array}{c}\text { Maqki } \\
\text { i pieczyste }\end{array}$ & Bratenstücke & Gebratenes & $\begin{array}{l}\text { Mehl und } \\
\text { Braten }\end{array}$ & $\begin{array}{c}\text { Mehlspeisen und } \\
\text { Kuchen }\end{array}$ \\
\hline $\begin{array}{c}\text { Czarna } \\
\text { polewka }^{\mathrm{IV}}\end{array}$ & schwarze Suppe & „schwarze Suppe” & schwarze Suppe & Schwarzsauer \\
\hline $\begin{array}{c}\text { Chłodziec } \\
\text { litewski }\end{array}$ & Litauersuppe & "Chłodziec" & $\begin{array}{l}\text { litauische } \\
\text { Rahmsuppe } \\
\text { litauischer } \\
\text { Chłodnik }\end{array}$ & $\begin{array}{c}\text { litauische } \\
\text { (sahnenreiche) } \\
\text { kalte Schale }\end{array}$ \\
\hline Dębniak & Sauerwein & - & Met & Eichenschnaps \\
\hline $\begin{array}{l}\text { Wódka } \\
\text { gdańska }\end{array}$ & Danziger Schnaps & Danziger Lachs & Danziger Lachs & $\begin{array}{l}\text { Danziger } \\
\text { Schnaps }\end{array}$ \\
\hline $\begin{array}{l}\text { miód } \\
\text { lipcowy }\end{array}$ & Julimet $^{\mathrm{V}}$ & $\begin{array}{l}\text { Lindenblüten- } \\
\text { honig }^{\mathrm{VI}}\end{array}$ & Met & Lindenblütenmet \\
\hline
\end{tabular}
chodzi.

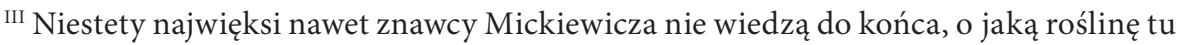

IV Należy zauważyć, że żaden z niemieckich ekwiwalentów nie oddaje symbolicznego znaczenia tej potrawy.

${ }^{\mathrm{V}}$ Miód lipcowy to właściwe miód z kwiatu lipy, co prawda lipa kwitnie właśnie w lip$\mathrm{cu}$, jednak w języku niemieckim nie występuje Julimet, tylko Lindenblütenmet.

${ }^{\text {VI } S ł o w o ~ m i o ́ d ~ w ~ j e ̨ z y k u ~ p o l s k i m ~ o z n a c z a ~ z a r o ́ w n o ~ p s z c z e l i ~ p r o d u k t ~(H o n i g), ~ j a k ~ i ~ w y-~}$ twarzany z niego miód sycony, czyli napój alkoholowy (Met). 
Już pobieżny rzut oka na tabelę pozwala zauważyć, iż najwięcej trudu przy oddawaniu realiów zadali sobie Lipiner i Buddensieg. Staranność ta jest niewątpliwie jednym $\mathrm{z}$ ważniejszych powodów oceniania właśnie tych dwóch spośród sześciu kompletnych przekładów jako najlepszych. Owszem, wiele w nich (choć mniej niż u pozostałych) nieuniknionych nieścisłości i uogólnień, które jednak nie tyle zmieniają opisaną rzeczywistość, co zamazują pewne jej rysy, wyraźniej przedstawione w oryginale (np. Haus w miejsce dworu, Gewehr miast karabeli). Nieliczne odejścia od znaczenia oryginału raczej nie wprowadzają w błąd, są przeważnie uwarunkowane względami formalnymi, jak zachowanie rytmu, unikanie rymów wewnętrznych, poszukiwanie rymu bądź aliteracji. Zwłaszcza w nazewnictwie roślin czy zapomnianych już potraw trudno uniknąć pomyłek, gdyż jest ono bardzo zróżnicowane regionalnie i nawet pośród polskich literaturoznawców nie ma zgody co do desygnatów opisywanych przez niektóre pojęcia użyte przez Mickiewicza.

Zupełnie inaczej przedstawia się sytuacja w przekładzie Panitza. Tak często ucieka się on do użycia pojęć ogólnych, że zachodzi podejrzenie o brak staranności. Zamiast niezabudek mamy u niego pozbawione wszelkiej symboliki Blümchen, sztucer to Gewehr, a szałwia - Heilkraut. Maleńki szczyr ${ }^{6}$ wyrasta na spory krzak (Strauch), a kalina kurczy się do rozmiarów niepozornej krzewinki (Heidelbeere). Przytrafia się mu obdarzenie żółtej dziewanny błękitnym i czerwonym kwieciem, a protagonistom każe czasem pić miód pszczeli (Honig) zamiast pitnego (Met). Nie był jedynym (sekunduje mu w tym Lipiner), który kazał Hrabi szukać ukrycia wśród najwyżej piętnastocentymetrowych liści babki (Wegerich) zamiast w łopianach. Popełniając takie omyłki, wywołuje niezamierzenie efekt komiczny - na szczęście przydarza mu się to najczęściej w scenach, które i sam autor zabarwił humorem.

Błędy z kategorii wołających o pomstę do nieba przytrafiły się Walburdze Friedenberg. Natchniona być może upadkiem mieszczańskich obyczajów, który nastąpił w latach sześćdziesiątych i siedemdziesiątych ubiegłego wieku, każe ona Zosi, niewinnej panience, w domu pełnym obcych męż-

${ }^{6}$ Nazwę szczyru przetłumaczyli Lipiner i Friedenberg poprawnie jako Bingelkraut. Cóż, gdy Mickiewicz, pisząc o szczyrze, zupełnie inną miał na myśli roślinę! Otóż chodziło mu zapewne o szarłat zwisły, bo jego „barwiste ogony” zwieszały się z porośniętych dachów zaścianka. Panitz, jako specjalista od uproszczeń, użył określenia krzak, Buddensieg wybrał Hirse (proso), które również ma zwieszające się kity, jednakże trudno je określić jako „barwiste”, gdzie indziej określane u Mickiewicza jako koralowe. 
czyzn wychodzić do ogrodu w halce (Unterkleid), myląc współczesne znaczenie słowa bielizna $\mathrm{z}$ dawniejszym. Zwyczaj przyoblekania przez Zosię bielizny, czyli sukni porannej, przed południem, a przebierania się do obiadu, świadczy o jej schludności i znajomości zwyczaju, natomiast wychodzenie do drobiu w bieliźnie osobistej oznaczałoby w każdej epoce wyjątkową niechlujność.

Sztuciec to dawna nazwa sztucera. W oryginale czytamy:

Widno, że hrabia kędyś ruszył z całym dworem

I bardzo spieszył, bo drzwi zostawił otworem.

Widać, że się uzbrajał, leżały dwórurki

I sztućce na podłodze, dalej sztenfle, kurki

I narzędzia ślusarskie, któremi rynsztunki

Poprawiano.

Nazwa ta występuje zarówno w Panu Tadeuszu, jak i w Zemście Aleksandra Fredry. W książce Dawna broń myśliwska Aleksander Czerwiński cytuje Ignacego Bobiatyńskiego, współczesnego Fredrze znawcę broni:

Sztuciec ma powszechnie ściany wewnątrz rury gwintowane w kształcie ślimakowatym, używa się go pospolicie do strzelania grubego zwierza w odległości 80-150 kroków. Narżnięcia, czyli gwintów wewnątrz rury pospolicie daje się 6-8, a niekiedy 12 (Czerwiński 1997: 71).

W niemieckich tłumaczeniach mamy do czynienia ze stosowaniem ekwiwalentu Stutzen, ewentualnie uogólnienia Gewehr (Panitz). Dobór określenia nie powinien stanowić żadnego problemu, sztucery wszak używane były również w Niemczech. Rzecz wymaga jednak odrobiny znajomości przedmiotu, jako że dziś słowo to ma zupełnie inne znaczenie. W tę właśnie pułapkę wpada Friedenberg w swym przekładzie z roku 1977. Czy to dlatego, że minęła epoka, gdy każdy szanujący się mężczyzna był w posiadaniu broni palnej i zwykł polować, czy też zawiniła tu niewieścia nieznajomość rzeczy - dość, że dwururki leżały u niej na podłodze wraz ze sztućcami („mit Bestecken”), których wartość w starciu z grubym zwierzem można docenić najwyżej, gdy ów występuje na talerzu w postaci pieczystego. Jakże inną wymowę mogą mieć w towarzystwie sztućców kurki (u Friedenberg Hähne), wymieniane w następnym wersie... Jednak jakiś nieszczęsny niemiecki czytelnik, naoglądawszy się Ursusów ukręcających bykom łby, może pomyśleć, że mężni Polacy wybierali się na polowanie zbrojni w nóż, łyżkę i widelec! 
Zresztą byki i pozostała rogacizna zajmują niepoślednie miejsce w klasycznej literaturze polskiej. Tym bardziej nie wypada tłumaczowi mylić tura $\mathrm{z}$ żubrem, a tych $\mathrm{z}$ kolei $\mathrm{z}$ bizonem czy innym trawożerca.

Przeciętny Polak wie, że żubry mieszkają w Białowieży, a tury wybite zostały parę setek lat temu - ostatni ubity został ponoć w 1627 roku. Natomiast bizony z punktu widzenia Europejczyka należą ewidentnie do wyposażenia scenografii westernów. Nie inaczej było 200 lat temu. Bizony pasły się w milionowych stadach na preriach Ameryki i śladu po nich w Europie nie było. Turów za Mickiewicza nawet najstarsi ludzie nie mogli już pamiętać. Przeżyły jednak w języku polskim w zwrocie „silny jak tur”, uwiecznione przez Sienkiewicza w Krzyżakach jako godło gospody „Pod lutym turem” czy w tradycjach, jak turoń albo herbach miast (np. Chojnice) i rodów szlacheckich. W języku niemieckim zwierzę to - bos primigenius - nosiło nazwę Auerochse lub Ur. Żubr (bison bonasus), to po niemiecku Wisent, a bizon (bison bison) - Bison. Tłumacze Pana Tadeusza używają tych pojęć zamiennie. Trudno im się dziwić, skoro pomieszania tych gatunków nie ustrzegli się również autorzy słowników polsko-niemieckich, np. tego Wiedzy Powszechnej z 1988 roku, gdzie pod hasłem „żubr” widnieją obydwa określenia: Auerochse i Wisent.

Dla przeciętnego zjadacza chleba, nie kosztującego na co dzień żubrzyny ni mięsa bizona, jest to może obojętne. Dla zoologa, myśliwego czy smakosza - zdumiewające. Można jednak uznać, że ekwiwalencja dynamiczna dopuszcza zamianę pojęć o zbliżonym znaczeniu, zwłaszcza gdy zależy od tego forma stylistyczna, zresztą - może użytkownikom języka niemieckiego Wisent zdaje się dostojniejszym niż Auerochse, bo Ochse to po prostu wół, a to słowo w języku niemieckim oznacza nie tylko wykastrowane bydlę, funkcjonuje też jako wyzwisko.

Wyobraźmy sobie jednak taki obraz:
Żubr, brodacz sędziwy,
zadrżał we mchu, najeżył długie włosy grzywy,
wstaje na wpół, na przednich nogach się opiera
i potrząsając brodą, zdziwiony spoziera
na błyskające nagle między łomem zgliszcze...

A teraz zastąpmy tego żubra... rysiem. Jako dzikie zwierze żyjące w ostępach także mógłby być przestraszony odgłosami bitwy, słyszanymi po raz pierwszy w życiu. Lecz nie pasują do niego przymiotniki sędziwy, godny, a nade wszystko niemożliwe jest w jego przypadku potrząsanie grzywą 
i brodą, a to wszystko czyni on w wersji Friedenberg. Taki cudak zaskoczyłby nawet ewolucjonistów na tropie brakującego ogniwa ewolucji!

Podsumowując prace tłumaczy, nie można uniknąć powtarzania wciąż tych samych pojawiających się w wielu krytycznych opracowaniach wypowiedzi. Jednym z podstawowych obowiązków tłumacza jest doskonała znajomość warsztatu translatorycznego, tak aby mógł on przy tłumaczeniu literatury pięknej świadomie obrać jedną strategię, której koncepcję będzie realizował, pracując nad tłumaczeniem dzieła. Osoba zajmująca się tłumaczeniami, czyli pośrednictwem między kulturami, musi być wszechstronnie wykształcona. Nie tylko wiedza własna, podręcznikowa czy encyklopedyczna, lecz umiejętność wykorzystywania wszelkich dostępnych źródeł oraz współczesnych mediów może zadecydować o jakości wybranego ekwiwalentu. Wizja tłumacza-artysty, samotnie zamkniętego w swoim pokoiku ze stosem woluminów i walczącego z przeciwnościami tekstu należy do przeszłości. Koniecznością okazuje się pomoc ze strony specjalistów z różnych dziedzin. Ta interdyscyplinarna współpraca wymaga od tłumacza również kompetencji w zakresie komunikacji interpersonalnej oraz odrobiny skromności. Tłumacz może bowiem ożywiać martwe już światy, ale nie on je stwarza i dlatego nie powinien w nie ingerować.

\section{Literatura}

Czerwiński, Aleksander, 1997, Dawna broń myśliwska, Warszawa.

Kluge, Rolf-Dieter (red.), 1999, Von Polen, Poesie und Politik... Adam Mickiewicz 1798-1998, Tybinga.

Koller, Werner, 1997, Einführung in die Übersetzungswissenschaft, Wiesbaden. Mickiewicz, Adam, 1952, Herr Thaddäus oder Der letzte Einritt in Litauen. Ein Epos aus der Napoleonischer Zeit, Übersetzt von Siegfried Lipiner, Freiburg/Br.

Mickiewicz, Adam, 1955a, „Über die polnische Partei”, [w:] Ein Lesebuch für unsere Zeit, Weimar.

Mickiewicz, Adam, 1955b, Pan Tadeusz oder der letzte Einritt in Litauen. Versepos in 12 Büchern, nachdichtung von Walter Panitz, illustriert von E. Andriolli, Berlin (Ost): Aufbau Verlag.

Mickiewicz, Adam, 1963, Pan Tadeusz oder Die letzte Fehde in Litauen, übersetzt von Herrman Buddensieg, Zeichnungen von A. Uniechowski, München. 
Mickiewicz, Adam, 1977, Pan Tadeusz. Das Werk des großen polnischen Romantikers, ein Hohenlied der Heimatliebe, klangbildlich übertragen von Walburg Friedenberg, Wien.

Mickiewicz, Adam, 1980, Pan Tadeusz, czyli ostatni zajazd na Litwie. Historia szlachecka z roku 1811 i 1812 we dwunastu księgach wierszem, Wrocław.

Pazdan, Rachel, Buk, Agnieszka, 2003 „Danziger Lachs oder Wódka Gdańska”, Deutsch-Polnische Wechselbeziehungen in Sprache und Kultur. Studia Germanica Gedanensia, Gdańsk.

Pazdan, Rachel, Buk, Agnieszka, 2004 „Der Zauberstab des Übersetzers oder die Kunst, aus Holunder Heidelbeeren zu machen”, Zeszyty Naukowe Uniwersytetu Rzeszowskiego 17, Seria Filologiczna: Studia Germanica Resoviensia 3, Rzeszów.

Piebrock, Heinrich, 2000, Deutsche helfen Rußland bauen, Heft 26, Grundlagenverlag

Schlegel, August Wilhelm, 1846, Sämtliche Werke, Bd. XI, Berlin.

Sławkowa Ewa, Warchoł Jadwiga, 2000, Współczesne przekłady utworów Mickiewicza. (Studia kulturowo-literackie), Katowice.

\section{Lynx hunting with the fork - German versions of realia in Pan Tadeusz (summary)}

The text presents a analysis of the realia translation (i. e. armament, administration, botany, cuisine) in the selected most representative German translations of the national epos Pan Tadeusz by Adam Mickiewicz, the most important work of the Polish romanticism, which especially in the 1830s aroused interest in the whole Europe. It is also an attempt to examine to what extent inaccuracies in this field can influence the text's reception by its readers from other cultures. The comparison of four translations shows a different strategy chosen by every translator as far as the realia translation is concerned. Many aspects of the realia were generalized or even wrongly translated, which results in a deformation of the message conveyed by the author. Therefore not only should the translator have the knowledge of translation techniques but also be a comprehensively educated person who apart from their own and encyclopedic knowledge gathers information from all the available sources and modern media. It is necessary to use the help of specialists from various fields. 